\title{
The Oral Language Proficiency of Indonesian English Teachers
}

\author{
Teguh Budiharso \\ Mulawarman University, Indonesia \\ Email: proteguh@gmail.com
}

\begin{abstract}
:
This study reports an observation of the competencies of Indonesian secondary English teachers. An intensive observation over a two-week workshop session was performed involving 38 English teachers, with this group comprising 18 SMP English teachers and 20 SMA English teachers. Three aspects of the observation were identified for this study: competence in oral English, competence in written discourse, and the ability to motivate students in the classroom. This study revealed that English teachers lacked practice in speaking, resulting in an insufficient mastery of the oral use of English. In written discourse, the teachers showed a lack of mastery with rhetoric and the linguistic aspects of writing. In terms of strategies to motivate students in the classroom, the teachers generally lacked self-confidence.
\end{abstract}

Keywords: English proficiency, oral Language proficiency, teaching; competence

\section{Introduction}

This paper concerns the oral language proficiency of English teachers in junior secondary schools (SMP) and senior high schools (SMA) in Indonesia. In term of proficiency, we include the oral use of English for teaching in the classroom and for presentations and explanations toward certain subjects. This indicates the level of qualification in oral communication that teachers should accomplish.

Oral language proficiency is crucial for English teachers because it is the foundation on which they build their competencies. Various studies (Murdoch, 1994; Richards, 2010; Gan, 2012; Tarman \& Chigisheva, 2017) admit that there is a general consensus that language proficiency is the foundation of a non-native teachers' ability to teach English as a Second Language (ESL) and fulfill their future professional role (Murdoch, 1994) through many teacher-training programs. Language proficiency not only makes a contribution to teaching skills, it also leads to a greater confidence in a teacher's teaching ability and a good sense of professional legitimacy (Richards, 2010 as cited in Gan, 2012, p.55).

As teachers should endeavor to use English in the classroom as the medium of instruction, the way they demonstrate their own mastery of oral language will affect students' perceptions and comprehension (Tarman, 2016). In classroom settings, a teacher's performance with oral language represents a model for the learners, so students should imitate and internalize it in their own performances (Murdoch, 1994; Richards, 2010; Gan, 2012). The reality, however, 
seems to indicate a strong tendency for Indonesian English teachers to speak in their native language during classroom presentations. This may be because they actually lack sufficient proficiency in oral English to adequately explain subject-specific topics in English, or it may be motivated by a belief that speaking in English for entire sessions would require more energy and endurance when compared to explaining lessons in their native language (Bashruddin \& Qayyum, 2014; Richards, 2010; Gan, 2012).

The essence of oral proficiency and the need for it in the classroom for professional function is controversial. Bashruddin \& Qayyum (2014, p.1) report that there is a belief that anyone who can speak English fluently can also teach it. This is because in many contexts, teaching is equated to translating English into the native language. In reality, it seems many teachers barely know how to speak English themselves, yet they are given the responsibility to teach it.

Furthermore, Bashiruddin \& Qayyum (2014) undertook a global survey of English-language teachers in 89 countries and found that in $21 \%$ of the cases, the teacher mentioned that they were not specifically qualified to teach English. This demonstrates that the issue of English teachers not holding relevant qualifications is not just anissue in Indonesia. Of course, this does not mean that merely gaining a qualification in English equips one to teach English. Nevertheless, holding a degree in English is an important indication that a teacher possesses the relevant subject knowledge, because this can enhance professional confidence and increase the motivational level of a teacher.

Littlewood (2007) and Carless (2004) report that some secondary school English teachers in Asia often lack confidence when conducting communication activities in English, because the teachers themselves feel that their own language proficiency is insufficient to engage in communication or deal with students' unforeseen needs. In the context of ESL teacher education, Murdoch (1994) asserts that language proficiency will always represent the bedrock of an ESL teacher's professional confidence. Richards (2010) also states that language proficiency is the most important skill among the various dimensions of expertise in language teaching.

Despite internal factors that show a limited proficiency in oral English, Richards (2001) also takes the view that teachers' statuses and appreciation of their teaching jobs, as well as their salaries, affect their motivation to acquire proficiency through further qualifications. Language teachers often suffer from poor employment conditions, and they are not always recognized as trained professionals with specialized skills and knowledge. In addition, the statuses of ESL teachers in mainstream education in many parts of the world are of problematic, and it represents one of the major obstacles teachers face. The broader issue here is whether teachers are treated as professionals or simply regarded as members of a workforce (Richards, 2001, p.205).

Following the view of Richards (2001), this paper argues that the English language is being taught in less-than-ideal conditions in Indonesia. In junior and secondary schools throughout Indonesia, ESL teachers work in mainstream classrooms, often in highly varied and unpredictable situations. ESL is not a curriculum subject, so it needs to be delivered through the content of other subjects. ESL teachers also do not generally have sole control over classroom management, often having a class for various subjects for just a limited number of hours per week. English is taught indifferent ways according to the circumstances. Indeed, there are no 
established and accepted disciplinary teaching procedures and no clearly defined outcomes that are relevant to the learners' needs.

The underlying point of view has brought this study to several observations that suggest that some typical disadvantages need to be addressed. Specifically, this study is intended to investigate (1) problems on oral English proficiency and (2) problems with delivering oral English proficiency in the classroom.

\section{Literature Review}

\subsection{Language Proficiency}

Linguistically, oral language proficiency is defined as a complex system that relates to sounds, where meaning is derived from three components: phonological awareness, semantics, and syntax. Phonological awareness in oral language represents an understanding of how the smallest of sounds, or morphemes, are combined. There are also semantic components in oral language (Mondo Publishing, 2007). Oral language also comprises three components: form, vocabulary, and pragmatism. The form includes the phonology, morphology, and syntax in how words are constructed in the sentence or discourse level to convey meaning. The content concerns the message or meaning of what is being expressed, and it includes the vocabulary and semantics. The last component, pragmatism, constitutes the purpose driving the expression being used, such as sharing information or expressing needs (Mondo Publishing, 2007).

Oral language simply cannot develop in a silent classroom, because learners need to be surrounded by a spoken language that is understandable and comprehensible in order to develop their own language use (Echevarria et al., 2000). The two most important elements for the development of oral language are therefore a comprehensible input and social interaction (Peregoy \& Boyle, 2005).

\subsection{The Oral Competency of English Teachers}

Teachers have been the focus of teaching perspectives, because teachers play a key role in the success of education. A teacher's competency in the use of oral language is considered the first skill necessary to attain. In English instruction, an English teacher is first needs to possess three minimum requirements: First, an English teacher should have a non-discouraging personality. Second, an English teacher should have adequate classroom command of the language being taught. Third, an English teacher should have adequate presentational skills (Long \&Richards, 1987, p.16).

The language policy has a direct impact on the instruction, and it is considered a crucial factor in planning instruction programs (Richards, 2010). Therefore, discussion of the effectiveness of teaching and ways to improve the achievements of learners has been conducted from various perspectives, such as the role of a teacher in manipulating teaching methods, material design, curriculum and syllabus knowledge, and evaluation strategies (Peregoy \& Boyle, 2005).

The minimum requirement of a teacher as a professional, as outlined by Long \& Richards (1987:16), includes an awareness of individual learners and of his or her status as a teacher. This means that teachers should generally possess and display dedication to learning in general and to language learning in particular. The professional aspect entails two parallel and continuous concerns: First, a teacher should have a high degree of awareness of the learners as individuals, their progress and difficulties, and the best means of promoting their continued learning. 
Second, a teacher should have a high degree of self-awareness as a teacher, including making conscious efforts to improve his command of a foreign language, taking steps to avoid a gradual attrition of his or her language ability (which sometimes occurs with the passage of time), and seeking ways to improve and extend his or her understanding of the profession by staying appraised of changing ideas and techniques.

Williams (1973, p.107) admits that it can be a very difficult matter for teachers to teach English when their native language is not English unless careful training is provided to them to improve their skill in English. Teaching competencies that a successful English teacher should accomplish, according to Williams (1973), include a good command of grammar, a mastery of phonetics, and an extensive knowledge of vocabulary and its usage. Girard (1974:102) adds three teaching skills to this: a teacher as a model, a teacher as a technician of language teaching, and a teacher as a psychologist. By being aware of their positions, a teacher can solve and motivate students with ease. As a model, a teacher can demonstrate his or her use of the spoken language. As a technician of language teaching, he or she must be able to make his pupils understand the language and use correct pronunciation, thus developing students' communicative skills. Finally, as a psychologist, a teacher must be well aware of all his or her pupils' individual problems and be capable of coping with them, as well as creating mutual confidence and sympathy.

More recent literature that considers oral proficiency to be necessary for effective teaching includes the theory of Richards (2010). Richards outlines ten specific language competences that a language teacher needs in order to teach effectively. Each of these language competences is closely related to a teacher's ability to speak the target language fluently and confidently in the classroom (Gan, 2012).

\section{Research Methodology}

This study employed a qualitative approach and used classroom-based observation in its research design. It observed the oral performance of English teachers during teaching sessions in the classroom, with them using English as the language of instruction in various classroom settings. While conducting the observations, the researcher was helped by three collaborative researchers. These assisted in observing the classrooms and assessing each teacher's individual presentation and interview. The collaborators also contributed to the research in terms of the data analyses by helping in the member-check and triangulation processes to validate the data.

An intensive observation over a two-week workshop session was performed involving 38 English teachers, with this group comprising 18 SMP English teachers and 20 SMA English teachers. All participants held a master's degree in English language education, and they had on average been teaching for 8 years at their schools. Participants were recruited from SMAs and SMPs in Samarinda, and the research was conducted in July to September 2018.

The data for this study were therefore collected through observation, checklists, and interviews. Observation was used to collect data on teaching performance in the classroom, thus identifying the English teachers' oral language proficiency in classroom settings. A team of four researchers performed the observation at the same time, and each teacher was observed three times. During the observations, a checklist derived from Richard's (2010) scheme of oral proficiency was used.

The data for this study were collected and analyzed inherently throughout the process of observation. As long as a single datum was brought out, analyses were carried out and 
administered. As such, this technique was employed for every category of data, and the result was conformed with respect to the data resulting from further observations. In this way, data for oral performance retrieved from the first observation were inherently interpreted with respects to the second and subsequent observations. This technique was intended to be used, because qualitative data could be best analyzed this way. In order to confirm the coherence and stability of the interpretation, data triangulation was applied. To this purpose, a set of interpretations for some data was systematically prepared by the researcher. Each point was then cross-checked by the research team. A final interpretation was then given that accorded with the degree of appropriateness for the whole analyses process.

\section{Finding}

\subsection{Problems of Oral English Proficiency}

Oral language proficiency was evaluated using a checklist derived from the ten competences given by Richards (2010). This checklist covers language aspects and language competencies. Table 1 suggests that $20 \%$ to $30 \%$ of the 10 English teachers experienced problems with fluency, accuracy, and speech when using oral language in the classroom. In terms of language competencies, $30 \%$ to $60 \%$ respondents were constrained in the 10 aspects of oral language proficiency while teaching in the classroom. Four oral proficiencies were identified as being the main problems: (1) maintaining use of the target language in the classroom, (2) maintaining fluent use of the target language, (3) using appropriate classroom language, and (4) giving correct feedback on learners' use of language.

Table 1. Assessment on Performance on Teaching Practice

\begin{tabular}{|c|c|c|c|c|c|}
\hline No & Subject of assessment & 1 & 2 & 3 & 4 \\
\hline \multirow[t]{6}{*}{$\mathrm{A}$} & Language aspects & & & & \\
\hline & 1. Vocabulary & & 4 & 4 & 2 \\
\hline & 2. Grammar sentence patterns & & 5 & 3 & 2 \\
\hline & 3. Fluency or flow of expression & 3 & 4 & 2 & 1 \\
\hline & 4. Accuracy & 2 & 6 & 1 & 1 \\
\hline & 5. Speech & 2 & 4 & 3 & 1 \\
\hline \multirow[t]{11}{*}{$\mathrm{B}$} & Language competences & & & & \\
\hline & 1.Provide good language models & 4 & 3 & 2 & 1 \\
\hline & 2. Maintain use of the target language in classroom & 5 & 3 & 2 & \\
\hline & 3. Maintain fluent use of the target language & 6 & 3 & 1 & \\
\hline & 4. Give explanation and instruction in the target language & 3 & 4 & 2 & 1 \\
\hline & $\begin{array}{l}\text { 5. Give examples of words and grammatical structures and } \\
\text { give accurate explanation (e.g. vocabulary) }\end{array}$ & 4 & 3 & 2 & 1 \\
\hline & 6. Use appropriate classroom language & 5 & 2 & 2 & 1 \\
\hline & 7. Monitor his or her own speech & 4 & 3 & 3 & \\
\hline & 8. Give correct feedback on learner language & 5 & 3 & 2 & \\
\hline & 9. Monitoringpupilunderstanding & 4 & 4 & 2 & \\
\hline & 10. Motivating \&Encouragingpupilself-evaluation & 3 & 4 & 2 & 1 \\
\hline
\end{tabular}

(1-Needsseriousattention; 2-Satisfactory; 3 -Good;4-Outstanding)

With regard to the language aspects of oral use, fluency and accuracy, these are crucial. Fluency is the key to ease of speaking, where a speaker can converse without apparent difficulty and use academic vocabulary without exhibiting pauses or stumbles or needing to search for the right 
words. Topics, especially familiar academic topics and those that are part of the classroom routine, should be easily described (Stein, 1999). Fluency should arise frequently in teaching sessions when teachers use English for the entirety of a teaching session. Similarly, the problem of accuracy also manifests itself. Accuracy involves the correct use of linguistic structure. An effective way to provide an oral focus on form is by providing linguistic feedback. Linguistic feedback allows the students to learn that something in one of their utterances would not be entirely accurate or acceptable for a native speaker (Stein, 1999).

\subsection{The Development of Oral English Proficiency}

The development of good oral English was the main problem for the teachers. Awkward oral English is a major indication of the speaking ability of the teachers. Inaccurate utterances, illformed grammar and structure, and lack of fluency were dominant in every teacher, whether they were speaking in interaction or presenting topics in front of the class. The oral English performances of the teachers were essentially characterized by(1) inaccurate pronunciation, (2) ill-formed utterances, (3) low speaking speed and lack of fluency, (4) difficulty understanding what others were saying, and (5) difficulty presenting topics in English.

Inaccurate pronunciation manifested in many spoken words. Some words-such as thank, question, high, suggestion, supply, and so on-were mispronounced. When sentences requires extensive contents to express various ideas, ungrammatical sentences frequently appeared. The teachers showed problems with the use of "to be + verb 1" and "to be" for nominal, adjectival, and adverbial sentences. In terms of their speed and fluency of speaking, the teachers frequently showed "pause and stop" in their utterances, indicating a lack of practice in English speaking and a limited mastery of English vocabulary. Erroneous inferences from speaking occur frequently, resulting in an incorrect interpretation of the message. In addition, serious problems arose when teachers tried to present particular topics in a teaching presentation. The topics were perceived through a single perspective, and the discussion did not vary, nor was it extended to other relevant contexts.

The results of the interviews also revealed problems in the development of oral English skills, as indicated by (1) a lack of practice, (2) inadequate vocabulary, (3) a lack of command with grammar, (4) a lack of opportunity, and (5) low levels of motivation and belief.

\subsubsection{Lack of Practices}

A lack of practice refers to how often a teacher should speak in English in order to improve their skills. Of the 10 teachers, $80 \%$ claimed they lacked practice in speaking English, and this was the primary areas on for their difficulties in developing oral English skills. They confirmed that the job of teaching in their contexts, according to the teachers, does not require high degree of oral English skill. To them, classroom activities need not necessarily be conducted in English to achieve their goals. The frequent use of English with students, both within the classroom and outside it, may influence their quality of communication. However, the environments surrounding the teachers' jobs do not demand the oral use of English. Student's exposure to oral English is therefore limited, and supporting facilities that help develop English for communication are trivial. Therefore, there are few models for the use of oral English, and the motivation to use English for communication is not developed. What is more, the teachers also face challenges to the natural development of their command of English, including language attrition, a background focus on low skill levels, and limited exposure to teaching and speaking 
in English. These are all major and reasonable arguments for why the English teachers did not speak English so well.

\subsubsection{Inadequate Vocabulary}

Gan (2012) claims that a lack of vocabulary is regarded as a major obstacle to spoken communication, and this was a prevalent concern among teachers. The current study revealed that $90 \%$ of its participants admitted to having problems with vocabulary during the presentation of lessons where subject-specific terms needed to be used. Vocabulary is a major reason for why the teachers sometimes could not express themselves clearly and appropriately. They also claimed that their limited vocabularies directly contributed to a lack of fluency in their speech.

\subsubsection{Grammar as the Stumbling Block}

Incorrect grammar presents a stumbling block to speaking correctly. To speak fluently, $80 \%$ of the teachers believed that they needed to improve their use of grammar. Correct grammar is also believed to affect confidence when speaking. Gan (2012) argues that to ensure grammatical accuracy, teachers must think about the particular grammatical item involved before speakingthe utterance. One teacher claimed, "In speaking, you will not think too much what you are going to say. You have no time to think, and you have to improvise. When speakers rely on 'feel' for correctness without prior planning, they will make grammatical errors."

\subsubsection{Imperfect Pronunciation and Intonation}

Imperfect pronunciation and intonation are oral-proficiency problems that the teachers face when they use oral English, and this was affirmed by $100 \%$ of the participants. They claim that some words, especially those words that have been newly learned, are unfamiliar and they need to consult a dictionary to learn how the words should be pronounced with the correct intonation. Even some familiar words are not pronounced correctly, however. In oral communication, the teachers strongly stressed how they had to speak carefully in order to focus on pronouncing certain words so they sound accurate. "When I speak fast, there will likely be inaccuracies in some sounds," one teacher mentioned.

\subsubsection{Inadequate Opportunities to Speak English in Class}

Opportunities to speak English in the classroom are believed to be lacking, and the teachers did not try to initiate a belief that the English language should be used in a "bilingual context," asserting a fifty-fifty split in language use. Of the 10 respondents, $70 \%$ claimed they did not have enough opportunity to speak English in the classroom. It is evident that teachers explained teaching materials in English and also conducted interactions in English, but the way in which they interacted was not in the context of expressing the ideas an individual has in mind. The interactions should also rely upon the teaching materials prescribed for certain genres.

\subsubsection{Low Motivation and Belief}

A motivation to use English in the classroom was stated by $50 \%$ of teachers, and a belief about using English in the classroom was identified in some $60 \%$ of the teachers. Overall, $70 \%$ of teachers suggested using both English and Indonesian in their classrooms. In practice, of 10 teachers, only 1 (10\%) used mostly English, 2 used more English, and 7 used a mix of both English and Indonesian. Their motivation to use English raises, however, when the teachers 
want to give exposure to new teaching materials, but their belief declines when they find that most students do not fully understand the material if they use English more than $60 \%$ of the time.

Therefore, the teachers tend to merely discuss the textbook contents due to a fear of making mistakes. Not teaching creativity, innovating class dynamics, initiating different models of linguistic knowledge, or using teaching strategies in which English is the medium of instruction have restricted their abilities. Demonstrating motivation to students is hard to initiate, and a classroom's atmosphere can be monotonous, if the teachers tried to deliver in English.

\section{Discussion}

This research demonstrates that oral English proficiency functions as a foundation of an English teacher's competencies. In the Indonesian context, where English is an additional language, typical evidences appear differently in various settings.

This study revealed that a teacher's competence in oral English is first affected by his or her ability in various language aspects, including grammar, vocabulary, accuracy, and fluency. A lack of skill with these language aspects even contributes to the apparent impact that English teachers lack the confidence to use English during a teaching session. This study implies that the teachers' knowledge of English needs to be polished, and teaching performance needs to be supported with careful training. In a wider sense, a teacher is the human agent responsible for presenting teaching material to learners. He or she may be either physically present or somewhat remote in the case of self-study courses. Teachers should fulfill the minimum requirements for their role (Long \& Richards, 1987).

Problems in developing oral English are highlighted by Williams (1973). Self-confidence in the use of oral English increases the ease and speed in which a teacher conveys knowledge, and vocabulary and grammar is greatly affected by the mastery of a language. In contrast, the imperfect mastery of a language's aspects results in inaccurate conveyances and ill-formed utterances that lead to "more pauses and stop and start" during speech, which was found to be characteristic in the teachers' oral English (Stein, 1999).

Gan (2012, p.54) advocates that performing in an underdeveloped language tends to impose a large burden on the teacher when performing his or her job. Gaps in lexical knowledge can seriously compromise spoken fluency, so it is very hard for such an individual to engage in the higher-level, strategic aspects of communicating meaning if his or her mind is saturated with lower-level second-language processes.

When communicating with others, difficulties in understanding oral English present another major problem. Referring to Girard (1974), Richards (2010) and Gan (2012), where the teacher is a model, technician, and psychologist, this finding deserves much consideration. A sound command of grammar, good pronunciation and phonetics, and a mastery of vocabulary are significant language proficiencies for teachers. The teachers find it hard to use oral English on any occasion because they are not confident about saying things. To act as models, their pronunciation, grammar, and fluency are unsatisfactory. This therefore determines the teachers' performance to a certain extent.

Thus far, there has been an incorrect view from teachers that teaching grammar can be excluded from teaching strategies. As the focal objective of teaching English is developing oral 
communication, where grammar is not the main emphasis, it is speculatively stated that grammar is a secondary factor when teaching English. Studies conducted by Sadtono (1995), Baradja (1985), and Budiharso (2016), however, demonstrate that grammar mastery indicates the level of a learner's competency. Grammar is at the base of English, and a mastery of vocabulary in turn relies upon the level of grammar mastery, so accurate utterances can be developed. Sadtono (1995) points out that grammar relates to language creativity, where through analogy, one pattern of ideas can be produced from another different idea for a different occasion. Hammer (2007) states that without some understanding of grammar, students would not be able to do anything more than utter distinct language items. Consequently, students must somehow learn the grammar of a language, because this is central to itsuse.

This study also discovered that the English teachers lacked some language competencies for oral language use in the classroom. Inadequate oral language use also implied restricting learners' involvement in the teaching process. The use of English as a medium of instruction not only indicates the language proficiency of a teacher-it leads learners to learn from a comprehensible input. The English language is a skilled subject in which the learners can only be successful if they actively participate in the teaching-learning process. Consequently, the interaction between the teacher and the learning situation is fundamental in oral work lessons (Syomwene, 2013, p.170).

In addition, when teaching in the classroom, the teacher is responsible for encouraging selfmotivation, triggering the endeavor, and developing skills. The teacher should drive students to be aware of their involvement in the classroom by presenting positive attitudes, habits, and skills. Through attitude, students are encouraged to take responsibility for their study, actively process the material, and undertake an individual endeavor. The transfer of habits equips students to manage their time, accurately process material, be critical of their own work, reflect on their lessons, and learn from their mistakes. Finally, the transfer of skills deals with utilizing sources of study for successful learning (Sadtono, 1995).

\section{Conclusion}

The objective of this study was to investigate the oral English proficiency of English teachers in Samarinda, Indonesia and identify any problems the teachers encountered in developing their oral English proficiency. A major finding of this study indicates that problems with oral English proficiency were present in terms of various language aspects and teaching components. The problematic language aspects included limited vocabulary, imperfect grammar, and poor accuracy and fluency when using the English language. Problems in their teaching competencies primarily lay in the application of oral English in the classroom as the medium of instruction.

\section{References}

Baradja, M.F. (1985). Kapita Selekta Pengajaran Bahasa.Malang: IKIP Malang.

Bashruddin, Ayesha \& Qayyum, Rabail. (2014). Teachers of English in Pakistan: Profile and Recommendation. NUMI, Journal of Critical Inquiry, 12(1): 1-19.

Budiharso, Teguh. (2016). Teaching Practice: Does It Substantiate Student-Teacher Performance. Surakarta: Center of Language and Culture Studies. 
Carless, D. (2004). Issues in Teacher's Reinterpretation of a Task-Based Innovation in Primary School. TESOL Quarterly, 38(4): 639-662.

Echevarria, J; Vogt M, and Short, D. J. (2000). Making content comprehensible for English language learners: The SIOP Models. Needham Heights, MA: Allyn Bacon.

Gan, Zhengdong. (2012). Understanding L2 Speaking Problems: Implication for ESL Curriculum Development in a Teacher Training Institution in Hong Kong. Australian Journal of Teacher Education, 37(1): 43-59.

Girard, Dennis. (1974). Motivation: The Responsibility of the Teacher. London, ELT Journal, 31 (2).

Hammer, J. (2007). The Practice of English Language Teaching. London: Longman.

Littlewood, W. (2007). Communicative and Task-Based Language Teaching in East Asian Classroom. Language Teaching, 40, 243-249.

Long, M.H and Richards, C.J. (1987). Methodology in TESOL: A Book of Reading. Singapore: Harper and Row Publishers.

Mondo Publishing. (2007). Oral Language Proficiency: the Critical Link to Reading Comprehension.

Murdoch, G. (1994). Language Development Provision in Teacher Training Curricula. ELT Journal, 48(3): 253-259.

Peregoy, SF \& Boyle, O.F. (2005). Reading, writing, and learning in ESL: a resource book for K-12 teachers. Boston, MA: Pearson Education Inc.

Richards, J. (2010). Competence and Performance in Language Teaching. RELC Journal, 41(2): 101-122.

Richards, J.C. (2001). Curriculum Development in Language Teaching. Cambridge: Cambridge University Press.

Sadtono, E. (1995). English Language Development in Indonesia: A Smorgasbord. A Paper Presented at the National Seminar on the Development of ELT in Indonesia, July 31, 1995. Malang: IKIP Malang.

Stein, Miriam. (1999). Developing oral proficiency in the immersion classroom. ACIE Newsletter, 2(3): 1-8.

Syomwene, Anne. (2013). The Teaching of Oral Communication Skills in the English Curriculum in Primary School in Kenya, European Scientific Journal, 9(28): 167-177.

Tarman, B., \& Chigisheva, O. (2017). Transformation of educational policy, theory and practice in post-soviet social studies education. Journal of Social Studies Education Research, 8(2)

Tarman, B. (2016). Innovation and Education. Research in Social Sciences and Technology, 1(1).

Williams, W.E. (1973). The Training of Teachers of English as a Foreign Language.ELT Journal, 28(4): 106-126. 